${ }^{2}$ Social Medicine Department, University of North Carolina at Chapel Hill, Chapel Hill, North Carolina, USA

${ }^{3}$ International Diagnostics Centre, London, UK

Correspondence to Dr Joseph D Tucker, International Diagnostics Centre, Keppel Street, London WCE1, UK; joseph.tucker@post.harvard.edu

Contributors MEG and JDT identified the posters, drafted the text and approved the final manuscript.

Funding US National Institutes of Health (NIAID R01A108366-01, NIAID P30-AI50410) and Brocher Foundation.

Competing interests None.

Provenance and peer review Commissioned; internally peer reviewed.

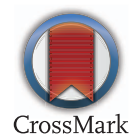

To cite Grewe ME, Tucker JD. Sex Transm Infect 2015;91:71.

Sex Transm Infect 2015;91:71.

doi:10.1136/sextrans-2014-051782

\title{
Syphilis cure posters
}

\section{REFERENCES}

1 Library of Congress. As old as creation Syphilis is now curable: consult your physician. http://www.loc.gov/ pictures/item/98516350/ (accessed 31 Aug 2014).

2 National Archives. "Both of these men had syphilis", 1941-1945. http://research.archives.gov/description/ Mary E Grewe, ${ }^{1,2}$ Joseph D Tucker ${ }^{1,3}$ 513979 (accessed 31 Aug 2014).

${ }^{1}$ Institute for Global Health and Infectious Diseases, University of North Carolina at Chapel Hill, Chapel Hill, North Carolina, USA
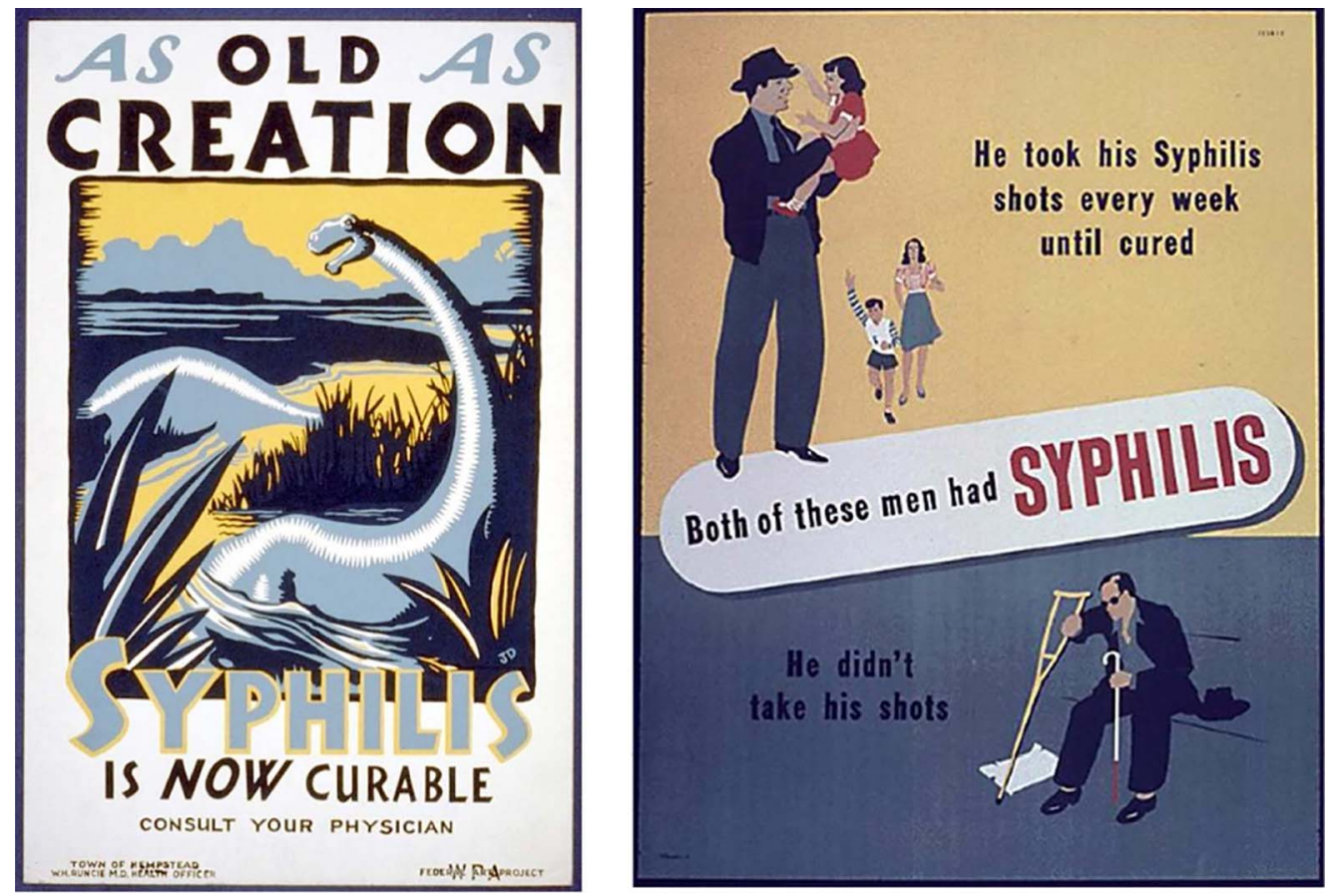

The development of syphilis cures profoundly shaped disease discourses and health promotion materials such as posters (above).

The left poster contrasts the ancient history of syphilis with its modern curability. ${ }^{1}$ The right poster highlights the effectiveness of the new cure, promising favourable outcomes for those who are cured and further disability for those who are not cured. ${ }^{2}$ The new curability of syphilis may have expanded testing as an entry point to cure. 